\title{
New Slit System for Stationary Crystal and Film X-Ray Topography Technique
}

\section{Lindegaard-Andersen, Asger}

\section{Published in:}

Review of Scientific Instruments

Link to article, DOI:

10.1063/1.1683502

Publication date:

1968

Document Version

Publisher's PDF, also known as Version of record

Link back to DTU Orbit

Citation (APA):

Lindegaard-Andersen, A. (1968). New Slit System for Stationary Crystal and Film X-Ray Topography Technique. Review of Scientific Instruments, 39(5), 774-775. https://doi.org/10.1063/1.1683502

\section{General rights}

Copyright and moral rights for the publications made accessible in the public portal are retained by the authors and/or other copyright owners and it is a condition of accessing publications that users recognise and abide by the legal requirements associated with these rights.

- Users may download and print one copy of any publication from the public portal for the purpose of private study or research.

- You may not further distribute the material or use it for any profit-making activity or commercial gain

- You may freely distribute the URL identifying the publication in the public portal

If you believe that this document breaches copyright please contact us providing details, and we will remove access to the work immediately and investigate your claim 
signal is then compared to a reference signal to give an error signal which is amplified and used to control the light source power supply. Use of the 814A dc power supply is particularly convenient for this purpose since not only can it be easily programmed by an external voltage but also its current limiting control can be set to prevent overdriving the lamp in case the light should be interrupted accidentally.

The performance of such a feedback system can be best demonstrated by comparing the thermocouple response with and without the feedback system connected. Since in the latter case the response is proportional to the light incident power and not to the number of incident photons, the feedback system needs to be connected, for a meaningful comparison, in such a way that constant incident power on the thermocouple is maintained. This condition can be achieved simply by disengaging the mechanical drive of the 10 turn potentiometer. The results obtained for our system are shown on Fig. 2. The maximum gain attainable in the feedback loop under stable operating conditions was found to be $10^{4}$. Stable operating conditions were achieved with a time constant of $0.1 \mathrm{sec}$ and a $6 \mathrm{~dB} /$ oct roll-off on the lockin amplifier. The particular time constant one should choose for a system designed around different feedback loop element would depend mostly on the characteristic of the light source. Under these conditions, as can be seen from Fig. 2, regulation of the light power output to better than $1 \%$ was achieved over a $0.3 \mathrm{eV}$ energy range centered at $1.05 \mathrm{eV}$. A larger energy range can be obtained if lower light power level is acceptable.

The system described above has been used extensively in the study of the lowering of the barrier height of Schottky diodes. The diode load resistance is of low enough value that the ac voltage appearing across it is a true measure of the short circuit photocurrent under all bias conditions. This voltage is amplified and detected by a second lockin amplifier similar to the one used in the feedback loop. The physical properties of Schottky barriers that were observed have been reported elsewhere ${ }^{6}$ and will not be discussed here.

The above described method results in an accuracy comparable to the one obtained by the extrapolation technique used by previous authors ${ }^{1-3}$ to measure similar changes in barrier heights. The main advantage of our system is the very short experimental time needed to measure a given change in barrier height. The feedback light control system has proved to be quite adequate for a photon energy range between 0.90 and $1.20 \mathrm{eV}$. It can be extended further into the infrared by using a higher power lamp and a higher comparison amplifier gain or by reducing the output power level desired.

The present system is relatively easy to set up. The short time needed to complete a whole set of measurements makes it worthwhile if one is planning to embark on a set of similar experiments.

${ }^{1}$ S. M. Sze, C. R. Crowell, and D. Kahng, J. Appl. Phys. 35, 2534 (1964)

2 A. I. Braunstein, M. Braunstein, and G. S. Picus, Appl. Phys. Letters 8, 95 (1966).

${ }^{3}$ G. W. Lewicki and C. A. Mead, Appl. Phys. Letters 8, 98 (1966).

${ }^{4}$ R. H. Fowler, Phys. Rev. 38, 45 (1931).

5 The $814 \mathrm{~A}$ power supply can be voltage programmed by applying the programming signal $(0-100 \mathrm{~V}, 0-20 \mathrm{~mA})$ between the + and the $A_{2}$ terminals.

'F. A. Padovani, Solid State Electron. 11, 193 (1968).

\section{New Slit System for Stationary Crystal and Film X-Ray Topography Technique}

\author{
A. LindegaARd ANDERSEN \\ Physics Laboratory III, Technical Universily of Denmark, \\ Lyngby, Denmark \\ (Received 27 April 1967)
}

$\mathrm{O}$ $\mathrm{NE}$ of the most critical parts in the experimental setup for the stationary crystal and film $x$-ray topography technique previously described ${ }^{1}$ is the fine Soller slit. This slit system is difficult to produce with a sufficient degree of accuracy and has been replaced by the system shown in Fig. 1. The new slit system consists of six identical, relatively coarse, transmission gratings $\mathrm{A}, \mathrm{C}, \mathrm{F}, \mathrm{E}, \mathrm{D}$, $B$ mounted in a channel made of aluminum. The gratings are made of $1 \mathrm{~mm}$ thick brass sheets. The width of the slits is equal to the width of the brass strips separating them. The gratings are aligned and the spacings between them are arranged in a certain sequence as shown in Fig. 2 . The distance between gratings is given by $x / 2^{n}$, where $x$ is the distance between the end gratings $\mathrm{A}$ and $\mathrm{B}$, and $n$ is an integer. $B y$ this arrangement one obtains that radiation from one slit in the first grating A passes the last grating $B$ only through the corresponding slit in this grating. Considering radiation from, e.g., slit 1 in grating A (Fig. 2) we see that grating $\mathrm{C}$ prevents radiation from passing through slits of even number in grating $B$; grating $D$ prevents radiation from passing through slits $3,7,11, \cdots$; grating $\mathrm{E}$ prevents radiation from passing through slits 5,13 ,

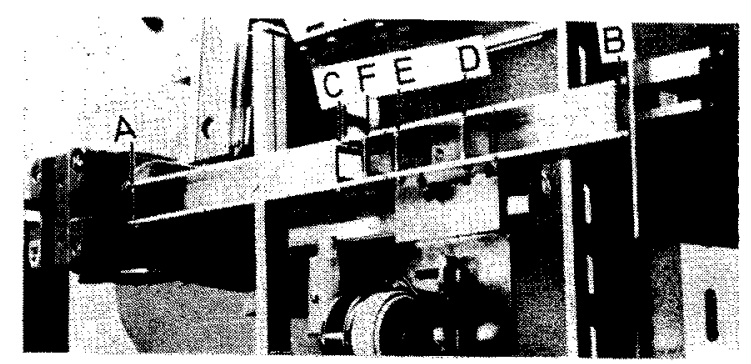

Fig. 1. Grating assembly A, C, F, E, D, B adapted to a Philips X-ray generator. 
FIG. 2. Geometrical arrangement of the grating assembly. Radiation from one slit (e.g., slit No. 1) in the first grating $A$ passes the last grating $B$ only through the corresponding slit in this grating.

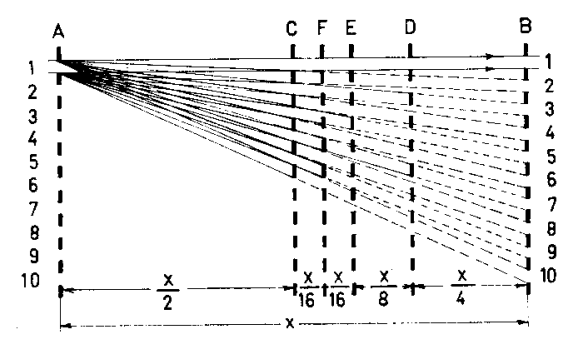

$21, \cdots$; etc. Thus, the grating assembly has the same effect as a Soller slit. For the equipment in use at this laboratory the width of the slits is $0.4 \mathrm{~mm}$ and the distance $x=400 \mathrm{~mm}$ resulting in a horizontal beam divergence of $2 \times 10^{-3} \mathrm{rad}$. The grating assembly was found easier to fabricate than a corresponding Soller slit of similar accuracy. The replacement of the fine Soller slit in the experimental set-up ${ }^{1}$ has resulted in a $50 \%$ reduction of the required exposure time and in a slight improvement of the resolution.

1 A. Lindegaard Andersen, Rev. Sci. Instr. 36, 1888 (1965).

\section{Operation of a Germanium FET at Low Temperatures}

\author{
E. C. KELM
}

Ford Scientific Laboratory, Newport Beach, California 92663

(Received 14 December 1967)

$\mathrm{F}^{\mathrm{o}}$ $\mathrm{OR}$ more than a decade the need for active devices which will function at low temperatures has been recognized. ${ }^{1}$ It is often desirable to amplify a weak signal generated at a low temperature, and match its impedance to a terminated cable as close to the point of generation as possible. The advantages to be gained by performing these operations at low temperatures are reduced thermal noise, improved frequency response, and reduced pickup of interfering signals.

In the search for active devices useful at low temperatures, the Texas Instruments TIXM12 germanium pchannel junction FET was studied. Typical characteristics at room temperature, measured on a lot of 100 units, were $g_{m}=10000 \mu \mathrm{mhos}$ and $I_{d s 8}=15 \mathrm{~mA}$. From 300 to $77^{\circ} \mathrm{K}$ these characteristics approximately doubled; from 77 to $4.2^{\circ} \mathrm{K}$ they increased only $10 \%$; from 4.2 to about $1^{\circ} \mathrm{K}$ they increased less than $1 \%$. This behavior suggests the possibility of testing circuits at liquid nitrogen temperatures with the assurance that they will perform similarly at liquid helium temperatures.
An experimental amplifier and an oscillator using TIXM12's were constructed. The amplifier circuit shown in Fig. 1 (a) has a $50 \Omega$ input impedance and is designed to operate into a terminated $50 \Omega$ cable. At $77^{\circ} \mathrm{K}$ it has a voltage gain of about 6 and is $3 \mathrm{~dB}$ down at $250 \mathrm{kHz}$ and $30 \mathrm{MHz}$. At $4.2^{\circ} \mathrm{K}$ the gain and bandwidth remained virtually the same as at $77^{\circ} \mathrm{K}$.

The noise properties were measured at 77 and $4.2^{\circ} \mathrm{K}$. The equivalent input thermal noise generated by $R_{1}, R_{\mathbf{2}}$, and $1 / g_{m}$ at $77^{\circ} \mathrm{K}$ is calculated to be $0.7 \mathrm{nV}-\mathrm{Hz}^{-1}$. At that temperature the measured noise of the amplifier from 250 $\mathrm{kHz}$ to $40 \mathrm{MHz}$ referred to the input was found to be substantially the value calculated. At $4.2^{\circ} \mathrm{K}$ the calculated thermal noise is $0.16 \mathrm{nV}-\mathrm{H} z^{-\frac{1}{1}}$, but the measured noise was found to be much greater. The equivalent input noise at $4.2^{\circ} \mathrm{K}$ as a function of frequency is shown in Fig. 2. The noise spectrum has a characteristic $1 / f$ dependence which is not present at $77^{\circ} \mathrm{K}$ in the range of frequencies studied. It is apparent that below $30 \mathrm{MHz}$ the noise will be increased upon cooling from 77 to $4.2^{\circ} \mathrm{K}$ by the appearance of $1 / f$ noise. The level of thermal noise calculated at $4.2^{\circ} \mathrm{K}$ will not be reached until a frequency well beyond practical operation.

The circuit in Fig. 1(b) is a simple oscillator employing a TIXM12. At $77^{\circ} \mathrm{K}$ and below it will oscillate at supply voltages from 1 to $20 \mathrm{~V}$. With proper choice of supply voltage, it exhibits a stability of $\pm 1 \mathrm{ppm}$ at $1.3 \mathrm{MHz}$ for periods of a few minutes.

The design of low temperature circuits using the TIXM12 presents few difficulties. The high value of $g_{m}$ attained at low temperatures solves many problems. The

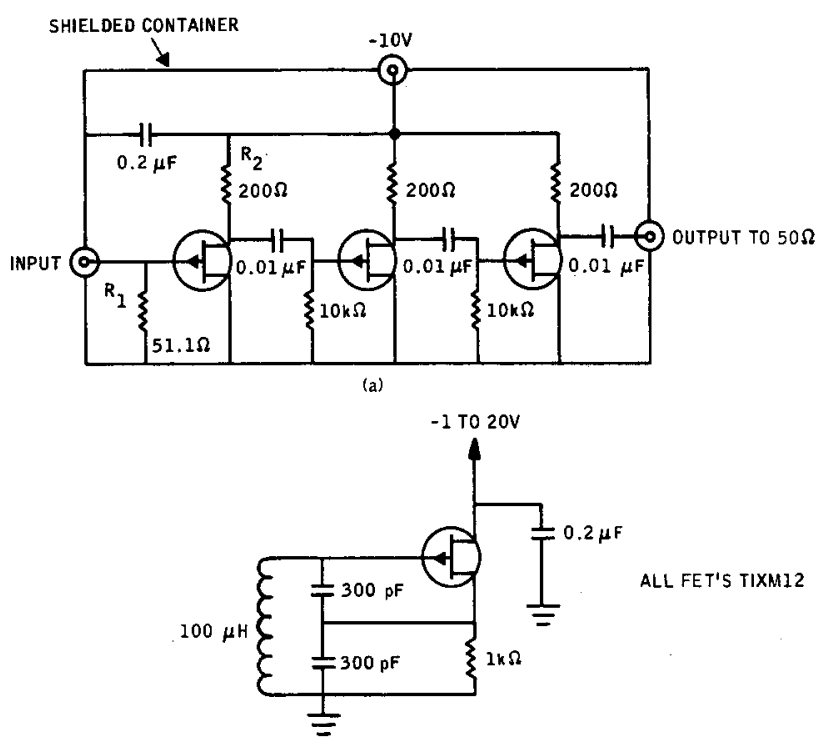

(b)

FIG. 1. (a) Schematic circuit of amplifier. (b) Oscillator. 